Abstracta Iranica Abstracta Iranica

Revue bibliographique pour le domaine irano-aryen

Volume 25 | 2004

Comptes rendus des publications de 2002

\title{
L'Orient des femmes. Lyon, Ecole Normale Supérieure («Signes »), 2002, 320 p., 16 pl. h.-t. coul., index.
}

\section{Jean-Pierre Digard}

\section{OpenEdition}

1 Journals

\section{Édition électronique}

URL : http://journals.openedition.org/abstractairanica/5165

DOI : 10.4000/abstractairanica.5165

ISSN : 1961-960X

Éditeur :

CNRS (UMR 7528 Mondes iraniens et indiens), Éditions de l'IFRI

\section{Édition imprimée}

Date de publication : 15 mai 2004

ISSN : 0240-8910

\section{Référence électronique}

Jean-Pierre Digard, «L'Orient des femmes. Lyon, Ecole Normale Supérieure (« Signes »), 2002, 320 p., 16 pl. h.-t. coul., index. », Abstracta Iranica [En ligne], Volume 25 | 2004, document 331, mis en ligne le 15 mars 2006, consulté le 25 septembre 2020. URL : http://journals.openedition.org/abstractairanica/ 5165 ; DOI : https://doi.org/10.4000/abstractairanica.5165

Ce document a été généré automatiquement le 25 septembre 2020.

Tous droits réservés 


\title{
L'Orient des femmes. Lyon, Ecole Normale Supérieure (" Signes »), 2002, 320 p., 16 pl. h.-t. coul., index.
}

\author{
Jean-Pierre Digard
}

1 Ce livre aux contours imprécis mais au contenu toujours stimulant se signale par plusieurs articles se rapportant au monde iranien. Dès le premier article de la première partie, intitulée "Représentations esthétiques de la femme orientale", Nadia Ali introduit le lecteur dans le vif du sujet, en traitant des « Représentations esthétiques de la femme orientale. Une approche du nu féminin en peinture persane » (pp. 21-34) à partir du $14^{\mathrm{e}} \mathrm{s}$. Les représentations picturales du corps féminin se caractérisent par une "absence de tout naturalisme, de modelé et d'individualisation qui répondent peutêtre à une volonté de se détacher de la réalité sensible» (p. 29), d'où il résulte que, devenu « un univers imaginaire, [...] le portrait devient un archétype » (Y. Porter). On a là une illustration de ce monde " imaginal ", intermédiaire entre raison et sens, analysé par Henry Corbin, notamment chez Sohravardî : ici, ce que montre l'image n'est pas le corps physique mais un corps «imaginal» qui manifeste surtout l'appartenance spirituelle de l'être.

2 Etudiant, quant à elle, l'« Ambiguïté des genres dans les peintures des manuscrits arabes et persans » (pp. 35-46), Eloïse Brac de La Perrière montre que la différenciation sexuelle dans les peintures de manuscrits persans opère moins par la physionomie des personnages que par le positionnement des corps; cette dénotation visuelle vient suppléer les défaillances des processus de dénotation linguistique, car ce positionnement permet d'introduire des différenciations de genre qui manquent à la langue persane.

3 Farzaneh Pirouz-Moussavi décèle, dans les «Représentations de la femme chez les Qâj ârs » (pp. 47-59), le passage de la femme, sous cette dynastie, d'un état de produit de consommation passif, à un motif essentiel de la promotion active de la personne et du pouvoir du monarque, selon des formes et avec des intensités variables selon les souverains. Sous Fatḥ 'Alī Šāh, la célébration du roi apparaît comme l'élément clé : de 
nombreux portraits rigides et conventionnels de ses épouses et concubines faisaient apparaître celles-ci comme des attributs royaux, les peintures érotiques étant reléguées sur le décor de petits objets (qalyān, récipients et boîtes divers). A l'inverse, l'absence de désir d'autoglorification chez Moḥammad Šāh libéra les artistes des canons antérieurs; des femmes européennes, représentées sur un mode réaliste, permirent l'émergence de la notion de sensualité en peinture. Sous Nāṣer ed-Dīn Šāh, enfin, des facteurs politiques, étrangers aux désirs personnels du roi, grand amateur de femmes, exercèrent une influence restrictive, notamment sur la représentation des femmes iraniennes. La femme apparaît aussi durant cette période comme un révélateur d'emprunts à l'Europe (comme celui du tutu des ballerines qui fit fureur dans le harem de Nāṣer ed-Dīn Šāh).

4 La deuxième partie du livre, intitulée "L'esprit et les lettres au féminin oriental ", s'ouvre sur une contribution de Živa Vesel, «Les femmes et la science dans l'Iran médiéval : la rareté des sources est-elle significative de la réalité ?» (pp. 75-83). Le constat de l'absence des femmes auteurs dans les sources écrites de la science arabe et persane médiévale amène l'A. à distinguer le champ de la connaissance scientifique de celui du savoir existentiel, non documenté, mais dans lequel on peut deviner une forte pratique féminine (médecine, astrologie, magie...) - un savoir autre, certes, mais qui bat en brèche le mythe de la femme captive et passive.

Une illustration de ce qui précède est offerte par l'étude du texte Haft peykar («Les sept princesses ») de Neẓāmī à laquelle procède Christine Van Ruymbeke («La femme et l'arbre dans la poésie de Nezâmi ", pp. 85-92) : les sept princesses représentent autant d'étapes sur la voie de la sagesse, la sensibilité féminine s'opposant ici au savoir masculin.

6 Pauline Lavagne d'Ortigue s'intéresse, elle, au "Ketâb-e Kusum Naneh : le livre des dames, ou l'inventaire imaginaire des coutumes et superstitions des femmes persanes » (pp.101-113). Ce petit ouvrage anonyme, satire des mœurs féminines de la fin de l'époque safavide, est attribué à un religieux eșfahānī de la deuxième moitié du $17^{\mathrm{e}} \mathrm{s}$. ; il a en outre été traduit du persan en anglais puis de l'anglais en français dans le première moitié du $19^{\mathrm{e}} \mathrm{s}$. L'A. s'intéresse d'abord au contexte - européen colonialiste - dans lequel ces traductions ont été publiés : le livre y est présenté comme une description quasi ethnographique de la vie des Iraniennes. En réalité libelle ecclésiastique à visée idéologique, il décrit de manière caricaturale et outrancière les mœurs féminines mariage, vie familiale, parure, toilette, séduction, magie... - à seule fin de stigmatiser leur prétendu relâchement.

7 Etudiant les « Métaphores et images féminines dans la poésie de Hâfez » (pp. 115-122), Laurence Chamlou montre comment, chez les mystiques iraniens, la femme peut être haussée au rang de guide spirituel, de " passeuse » entre l'ici-bas et l'au-delà.

Enfin, Chirine Anvar se penche sur «La féminisation de l'être aimé dans les traductions de Hâfez (1771-1813)» (pp. 123-132). Pour vaincre le flou qui résulte de l'indétermination du système pronominal de la langue persane, le traducteur se voit contraint de déterminer ce qui ne l'était pas. Or les implications de ce travail d'astreinte langagière ne sont pas seulement grammaticales; elles sont aussi philosophiques et religieuses car c'est à ses implications mystiques que tient une grande part de l'intraduisibilité du texte oriental, que les rationalisations occidentales se révèlent généralement impuissantes à rendre. 
9 Les parties III («Des femmes et de l'imaginaire du voyage ») et IV («Visions orientalistes au féminin ») traitent de divers pays du Moyen-Orient arabe, des Touaregs, du Pakistan et même de la Malaisie, mais restent muettes sur l'Iran, l'iranologue Leili Anvar-Chenderoff elle-même traitant ici des femmes turques, à travers le célèbre témoignage de Lady Mary Wortley Montagu. Comment ne pas s'étonner de l'absence, dans ces dernières parties du livre, de l'Iran contemporain dont le moins que l'on puisse dire est qu'il n'est pas resté sans nourrir le débat sur le statut des femmes en islam? Faut-il y voir un élément de pure conjoncture, simple manifestation de l'hétérogénéité et du déséquilibre de cet Orient des femmes, ou bien un fait structurel, conséquence de l'ostracisme dont les périodes récentes pâtissent dans certains cercles orientalistes? La question reste posée.

INDEX

Thèmes : 13.1. Iran

nompropre Nezāmī, Hāfez, Qājārs

\section{AUTEURS}

JEAN-PIERRE DIGARD

CNRS - Paris 